and report additional cases to public health authorities for investigation. Finding these previously undetected cases increased our COVID-19 reports to the public health department by $62 \%$.

The public health value added by surveillance and investigation of probable COVID-19 will become less clear as testing availability increases. Illustrating this point is our finding that, among the patients who would have been probable COVID-19 cases without being tested, fewer than $10 \%$ tested positive for SARS-CoV-2. Our findings highlight the need for more widespread testing for SARS-CoV-2 to appropriately allocate scare public health resources for COVID-19 investigation, isolation, and contact tracing.

Acknowledgments.

Financial support. No financial support was provided relevant to this article.
Conflicts of interest. All authors report no conflicts of interest relevant to this article.

Supplementary material. To view supplementary material for this article, please visit https://doi.org/10.1017/ice.2020.359

\section{References}

1. Standardized surveillance case definition and national notification for 2019 novel coronavirus disease (COVID-19). Council for State and Territorial Epidemiologists website. https://cdn.ymaws.com/www.cste.org/resource/ resmgr/2020ps/interim-20-id-01_covid-19.pdf. Published 2020. Accessed April 26, 2020.

2. Cases of coronavirus disease (COVID-19) in the US. Centers for Disease Control and Prevention website. https://www.cdc.gov/coronavirus/2019ncov/cases-updates/cases-in-us.html. Published 2020. Accessed April 26, 2020.

\title{
Coordinated outreach for veterans in long-term care facilities by an integrated Veterans Affairs healthcare system during the COVID-19 pandemic
}

\author{
Alexander Winnett $\mathrm{BS}^{1}$ (1), Lauren P. Jatt MD ${ }^{1}$ (1), Linda Sohn MD, MPH ${ }^{1,2}$, Marcia Lysaght DNP, RN, CENP ${ }^{2}$ (1), \\ Thomas Yoshikawa MD ${ }^{1,2}$, Steven R. Simon MD, MPH ${ }^{1,2}$, Christopher J. Graber MD, MPH ${ }^{1,2}$ and \\ Matthew Bidwell Goetz MD ${ }^{1,2}$ \\ ${ }^{1}$ David Geffen School of Medicine, University of California Los Angeles, Los Angeles, California and ${ }^{2}$ Veterans Affairs Greater Los Angeles Healthcare System, \\ Los Angeles, California
}

To the Editor-We read with interest the article by Guar et al ${ }^{1}$, highlighting the burdensome and dangerous effect of the coronavirus disease 2019 (COVID-19) pandemic on long-term care facilities (LTCFs), and their recommendations to support these vulnerable populations. Even large healthcare organizations have struggled to obtain the resources necessary to maintain normal operations, ${ }^{2}$ and these challenges may be accentuated in community LTCFs with fewer staff and less financial flexibility to obtain resources for the prevention and control of severe acute respiratory coronavirus virus 2 (SARS-CoV-2) outbreaks. In response to the sentiment described by Guar et $\mathrm{al}^{1}$ that "these extraordinary times call for unprecedented measures to protect our vulnerable LTCF residents" and their recommendation for "hospital systems to include LTCF settings as high-priority sites for increased access to respiratory viral tests, including for SARS-Cov-2, and [personal protective equipment]," we offer a brief description of unprecedented measures by a large, integrated, Veterans Affairs (VA) healthcare system to support community LTCFs facing resource limitations during the COVID-19 pandemic.

The VA Greater Los Angeles Healthcare System (VAGLAHS) is a multicampus healthcare system that includes a tertiary-care

Author for correspondence: Alexander Winnett, E-mail: awinnett@mednet.ucla.edu Cite this article: Winnett A, et al. (2021). Coordinated outreach for veterans in longterm care facilities by an integrated Veterans Affairs healthcare system during the COVID-19 pandemic. Infection Control \& Hospital Epidemiology, 42: 783-784, https:// doi.org/10.1017/ice.2020.326 hospital, several satellite clinics, and on-campus LTCFs. In response to the COVID-19 outbreak amongst residents of 2 of the on-campus LTCF wards, 1 of these LTCF wards was converted to a COVID-19 recovery unit (CRU) to provide subacute medical care specifically for SARS-CoV-2-positive individuals following acute-care hospitalization, separate from uninfected LTCF residents. ${ }^{3}$ During this outbreak, VAGLAHS had access to high-volume molecular diagnostic testing capacity and utilized universal, serial, surveillance testing of residents to identify and isolate individuals at risk of transmitting the virus. These resources allowed for effective control practices ultimately halting the outbreak, with no new infections after only 2 weeks. ${ }^{4}$

However, many veterans reside in community LTCFs that are also at risk of a COVID-19 outbreak but may have more limited access to resources needed to prevent or control an outbreak, such as high-volume testing and personal protective equipment. Recognizing this dilemma, VAGLAHS leadership followed the provisions of the "Fourth Mission" of the VA to help community facilities also dealing with the pandemic: to "improve the Nation's preparedness for response to war, terrorism, national emergencies, and natural disasters by developing plans and taking actions to ensure continued service to veterans, as well as to support national, state, and local emergency management, public health, safety and homeland security efforts." ${ }^{\text {" }}$ A VAGLAHS Long-Term Care COVID-19 (LTCCV19) working group was established to take action and coordinate outreach efforts. 
The LTCCV19 surveyed the leadership of 25 community LTCFs to assess needs and identify areas of potential assistance; 18 facilities responded, and to date, the VAGLAHS LTCCV19 has engaged in targeted support with 11 facilities. VAGLAHS staff completed twice daily telephone calls with the community facilities' administrators for real-time feedback on new cases of COVID-19 in residents and staff. For 7 facilities with testing limitations, the VAGLAHS LTCCV19 deployed registered nurses to assist in collecting specimens from veteran residents and to perform universal SARS-CoV-2 surveillance testing, and train community staff on specimen collection. Veterans with COVID-19 from community LTCFs have been admitted to the acute-care VA hospital for medical care, then to the CRU if their community LTCFs were not able to house them upon recovery. VAGLAHS staff trained in infection control were dispatched to community LTCFs to review on-site practices and strategize areas for improvement, including those listed by Guar et al. ${ }^{1}$

As Guar et $\mathrm{al}^{1}$ emphasize, to combat this pandemic we must fortify areas of our society at higher risk of both outbreak and severe disease, such as LTCFs. The SARS-CoV-2 virus clearly does not recognize institutional boundaries, and institutions with the resources and capacity to assist in this fortification can play a substantial role in protecting vulnerable members of our community, ultimately reducing the burden of the ongoing COVID-19 pandemic.

Acknowledgments. We thank Lauren Barrera and Rachelle Davis for their work coordinating and conducting outreach activities, and VAGLAHS staff for adaptability and dedication to caring for veterans in unprecedented ways during the COVID-19 pandemic. The views expressed in this article are those of the authors and do not necessarily represent the views of the Department of Veterans Affairs.

Financial support. No financial support was provided relevant to this article.

Conflicts of interest. All authors report no conflicts of interest relevant to this article.

\section{References}

1. Gaur S, Dumyati G, Nace DA, Jump RLP. Unprecedented solutions for extraordinary times: helping long-term care settings deal with the COVID-19 pandemic. Infect Control Hosp Epidemiol 2020;41:729-730.

2. Grimm CA. Hospital experiences responding to the COVID-19 pandemic: results of a national pulse survey March 24-27, 2020. US Department of Health and Human Services, Office of Inspector General website. https:// oig.hhs.gov/oei/reports/oei-06-20-00300.pdf. Published 2020. Accessed June 30,2020 .

3. Sohn L, Lysaght M, Schwartzman WA, Simon SR, Goetz MB, Yoshikawa T. Establishment of a COVID-19 recovery unit in an LTCF. J Am Geriatr Soc 2020 Jun 18 [Epub ahead of print]. doi: 10.1111/jgs.16690.

4. Dora AV, Winnett A, Jatt LP, Davar K, Watanabe M, Sohn L, Kern HS, Graber CJ, Goetz MB. Universal and serial laboratory testing for SARS$\mathrm{CoV}-2$ at a long-term care skilled nursing facility for veterans-Los Angeles, California, 2020. Morb Mortal Wkly Rep 2020;69:651-655.

5. Mission statement. US Department of Veterans' Affairs website. https://www.va.gov/about_va/. Published April 8, 2020. Accessed June 9, 2020

\title{
Are we forgetting the "universal" in universal masking? Current challenges and future solutions
}

\author{
Sonali D. Advani MBBS, MPH ${ }^{1,2}$ (1) , Michael E. Yarrington $\mathrm{MD}^{1,2}$, Becky A. Smith MD, Deverick J. Anderson MD, MPH ${ }^{1,2}$ and \\ Daniel J. Sexton $M D^{1,2}$ \\ ${ }^{1}$ Department of Medicine, Division of Infectious Diseases, Duke University School of Medicine, Durham, North Carolina and ${ }^{2}$ Duke Center for Antimicrobial \\ Stewardship and Infection Prevention, Durham, North Carolina
}

To the Editor-Many US hospitals have recently adopted policies mandating universal masking of all staff, visitors and patients. Universal masking is particularly important in preventing transmission to and from individuals who are asymptomatic or presymptomatic for coronavirus disease 2019 (COVID-19). ${ }^{1}$ The Centers for Disease Prevention and Control (CDC) estimates that $\sim 35 \%$ of severe acute respiratory coronavirus virus 2 (SARS-CoV-2) cases are asymptomatic. ${ }^{2}$ In addition, healthcare professionals (HCPs), patients, and visitors with atypical or very mild symptoms may more readily transmit SARS-CoV-2 in healthcare facilities without masking policies. ${ }^{3}$ Risk of exposure to SARS-CoV-2 in nonclinical areas within healthcare facilities may be overlooked.

The incidence of COVID-19 among HCPs decreased significantly after our health system adopted a universal masking policy. Unmasked exposure to another HCP rather than exposure to

Author for correspondence: Sonali Advani, E-mail: sonali.advani@duke.edu Cite this article: Advani SD, et al. (2021). Are we forgetting the "universal" in universal masking? Current challenges and future solutions. Infection Control \& Hospital Epidemiology, 42: 784-785, https://doi.org/10.1017/ice.2020.333 known infected patients resulted in most of the COVID-19 cases among staff after implementation of this policy. ${ }^{4}$ We recently surveyed 50 community hospitals within the Duke Infection Control Outreach Network and found that $90 \%$ of these hospitals had also adopted universal masking policies. However, we also determined that actual compliance with universal masking policies was suboptimal, particularly among staff outside of clinical care settings, including administrative offices, shared work rooms, and break rooms. Poor compliance in these shared spaces led to known exposures in some of these hospitals, leading to employee furloughs, a substantial burden of contact tracing, and unnecessary anxiety for exposed individuals. Here, we discuss our perception and understanding of the etiology of poor compliance with universal masking policies in healthcare settings, and we discuss proposed solutions as well.

\section{Inaccurate risk perception}

Overall, HCP compliance with protective measures such as universal masking often correlates with the level of risk they

(c) 2020 by The Society for Healthcare Epidemiology of America. All rights reserved. This is an Open Access article, distributed under the terms of the Creative Commons Attribution licence (http://creativecommons.org/licenses/by/4.0/), which permits unrestricted re-use, distribution, and reproduction in any medium, provided the original work is properly cited. 